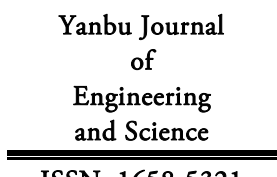

ISSN: $1658-5321$
Vol. 1, October $2010(1431 \mathrm{H})$

www.yic.edu.sa/yjes

\title{
CREATING AND MEASURING RELATIVE HARDNESS FEELING VIA MASTER-SLAVE HAPTIC GRIPPER
}

\author{
Tee Tiong Tay ${ }^{1}$ and Kiong Wong ${ }^{2}$ \\ ${ }^{1}$ Yanbu Industrial College, Saudi Arabia \\ ${ }^{2}$ Multimedia University, Malaysia
}

\begin{abstract}
This paper discusses the completed work in designing a master-slave haptic gripper system aiming to recreate the relative hardness feeling of different real test objects at the slave gripper to the user at the master gripper. The main contribution of this paper is to prove the feasibility of recreating the relative hardness feeling of real objects to the users as oppose to recreating the hardness feeling of virtual objects which has been proven to be feasible for quite some time. Three experiments involving twenty test subjects and fifteen pairs of test object combinations are conducted to evaluate the performance of the master-slave haptic gripper system. Experiments show that users at the master gripper end are able to differentiate the relative hardness level of the test objects handled by the slave gripper. The secondary contribution of this paper is the introduction of haptic index defined as a set of numerical value that describe the otherwise immeasurable subjective relative hardness level of an object felt by human. The proposed haptic index can contribute towards designing better robots and controllers that can feel the relative hardness of objects like in the human world.
\end{abstract}

KEYWORDS: Haptic, master-slave haptic gripper, haptic index and relative hardness.

\section{INTRODUCTION}

The term haptic is an adjective, comes from Greek word haptikos, meaning relating to the sense of touch or tactile [1,2]. Haptic interfaces are devices which enable human to interact manually with virtual environments. In general, the same interface hardware not only receives kinematics inputs from the human operator's limb, but also exerts a reflection force from the virtual environment on his limb [3]. Haptic interface is demanded to be safe, to work in wide operation space, and to present not only force at contact points but also weight feeling of virtual objects, to have no oppressive feeling when it is attached to humans, and to have no weight feeling of itself [4]. The goal of a haptic interface is to realistically stimulate the user so that the user feels like making contact with the actual environment [5]. A haptic system consists of a haptic input and a haptic output. Haptic input involves physical contact between the controller that is usually the host computer and the user or object. This contact may be via the hands or fingers. Haptic output is usually implemented by the host computer providing tactile, kinesthetic, force or combinations of the former feedback to the users. Practically, the effectiveness and quality of a haptic system is determined by its ability to provide a close to reality feedback to the user.

The research in haptic has gained prominence and importance in a lot of applications 
especially in telerobotics and telesurgery. Telerobotics are utilised in every imaginable applications from medical applications [6], nuclear industry [7], under sea explorations [7], space explorations, and so on. Unfortunately, the major problem hindering the progress of telesurgery and numerous other telerobotics applications is the user's lost of touch and feel of the object. For example, in telesurgery, surgeons lost the sense of touch and feel of their patients [8]. Currently, among the five sensations only visibility and audibility are widely transmitted remotely via telephony line and the internet. Transmission of tactile sensation is still under investigation [9]. In medical applications, haptic interface is an essential component in the implementation of medical simulator for various medical procedures such as endoscopy and laparoscopic procedure simulators [5]. Besides that, haptic technologies have the potential to be implemented in gaming applications, aviation industry, and home robotics in the near future. Haptic gaming system may enhance users' gaming experience where they can immerse themselves into the game thus creating a realistic gaming experience. Haptic is envisioned to be incorporated into aviation simulator producing a more realistic flying experience for future pilots. Haptic technologies can

also be implemented in vehicular crash simulator to better prepare future drivers in the event of a vehicular accident. The haptic index introduced and measured in this work from the force interactions between the robotic gripper and the test objects is useful in designing future robots that are able to work alongside humans.

Currently, haptic technology has seen some commercialization in the form of force and tactile feedback devices for research and product development purposes. Immersion
Corporation produces haptic devices namely CyberForce force feedback device, CyberGrasp exoskeleton and Impulse Stick force feedback joystick. Immersion Corporation also produces CyberGlove data glove, CyberTouch tactile feedback device, TouchSense tactile feedback touchscreen and Virtual Hand software [10]. Sensable Technologies has designed the popular Phantom haptic devices frequently used in haptic research in universities [11].

The primary aim of this work is to prove the feasibility of recreating the relative hardness feeling of actual object manipulated by a remote slave gripper back to the user at master gripper. The secondary aim is to measure the relative hardness feeling felt by user when manipulating an actual object.

\section{LITERATURE REVIEW}

Most research works in haptic can be categorized broadly into creating haptic tactile feedback $[5,9,12,13,14]$ and creating haptic force feedback $[4,15,16,17,18,19]$. Wagner et al. [12] designed a $6 \times 6$ tactile shape display that uses radio controlled servomotors to actuate an array of mechanical pins. The display can represent frequencies up to $25 \mathrm{~Hz}$ for small amplitudes. The system was able to convey small shape information at reasonable speeds for manual tactile exploration. Rakkanen et al. [13] designed a handheld prototype piezoelectric tactile feedback device integrated in touch screen to create haptic edges for buttons. The amplitude, the number of haptic bursts and the delay between the bursts was varied in the experiments. The results showed that less haptic bursts and less delay between the bursts were preferred by the users. The preferred level of the amplitude varied and thus should be adjustable. Samra et al. [14] designed a haptic tactile actuator that uses a spiral brush to simulate rough 
textures directly at the fingertip. The brush rubs against the users' finger through the aperture to create the perception of a rough surface underneath the fingertip. The speed of the brush can be controlled to simulate varying magnitudes of roughness. However, there are two groups of users that perceive roughness in an opposite manner from each other. This is an important observation that must be considered when designing tactile actuators.

Lawrence et al. [15] introduced rate hardness as a quality metric for hard virtual surfaces, and linked to human perception of hardness via a psychophysical study. A three DOF haptic interface is used to present pairs of virtual walls to users for side by side comparison. Forty nine subjects are tested in a series of three blocks of trials, where different virtual walls are presented in randomly ordered pairs. Results strongly support the use of rate hardness, as opposed to mechanical stiffness, as the more relevant metric for haptic interface performance in rendering hard virtual surfaces. The work seeks to provide low level performance metrics which can be easily measured, yet which have clear relevance to the user's perception. Experimental study shows that hard virtual walls are not necessarily the result of surfaces with high stiffness. The ratio of initial rate of change of force versus initial velocity upon penetrating the surface, rate hardness, can effectively substitute for large stiffness in user's perception of wall hardness. It is due to the relatively poor accuracy of the human kinaesthetic sense, which seems to be unable to distinguish stiffness as a ratio of static position to force.

Kikuuwe and Yoshikawa [16] designed a haptic display device with fingertip presser for motion and force teaching to human. The purpose of their research is to establish a method of virtual reality mediated motion and force teaching from human teacher to human student. According to them, for effective teaching, position and force information of the teacher's action have to be communicated to the students. They envisioned that the haptic device will eventually be used in cases of physical guidance such as tennis or golf coaching. Currently, the interference between the teacher's and student's bodies obstructs the teacher's natural motion, preventing effective teaching between teacher and student. Kikuuwe and Yoshikawa [16] said that position information is easy to display, but force information is difficult to display by conventional haptic devices. A haptic device could be used to communicate position information of the master's action by physically guiding the slave's arms or fingers. Force information, however, cannot be displayed by guidance. According to [16], it is impossible to display position and force information at the same time. A one degree of freedom haptic device that can display both position and force information at the same time is designed to solve the above mentioned problem.

According to Weir et al. [17], the challenge in the automobile industry is that currently there are few quantitative metrics to characterize switch-feel, and as such, no complete description can be given to suppliers and no method to verify their final product. In an ideal process, design requirements for switchfeel are quantitative and verifiable metrics based on psychophysical data. To determine these metrics, as well as to verify the produced switch, an accurate system to characterize the physical properties of existing switches is needed. A haptic display system is designed to act as a design tool to specify and explore switch-feel. The work in [17] demonstrates 
the need for quantitative metrics to characterize switch-feel, an actual object rather than just utilizing haptic for virtual objects manipulating on the computer screen. According to Nam and Park [18] it is of significant importance for haptic devices to allow human users to feel free in the free motion and stiff in the constrained motion. This performance measure is called realism or transparency. To improve transparency, the haptic device should be able to provide high sensitive force or torque output. However, the undesired but inevitable dynamic components of the haptic device, such as friction, inertia and backlash, may deteriorate its transparency. In order to overcome this limitation, they proposed a friction compensation model to improve the transparency of the hybrid haptic device in the free motion. By combining the small capacity active actuator with the large capacity passive actuator, the hybrid haptic device can provide wide ranged haptic reflection in the constrained motion thus guaranteeing the interface safety and haptic stability. A series of experiments were carried out using the proposed hybrid haptic device. Each test was repeatedly performed by three subjects who voluntarily rotate the knob of the device, changing the direction. All subjects reported that they could seldom perceive any jerky feel during the manipulation. They concluded that the proposed friction compensation can improve the transparency of the haptic device in the free motion in both qualitative and quantitative aspects.

Mulder et al. [19] investigated on using haptic guidance forces on the steering wheel as a means for driver support during curve negotiation. Haptic guidance forces allow drivers to remain in the direct manual control loop, avoiding known human factors issues with automation. The haptic guidance is developed to continuously generate relatively low forces on the steering wheel, requiring the driver's active steering input to safely negotiate curves. An experiment in a fixed base driving simulator was conducted, in which twelve young, experienced drivers steered a vehicle with and without haptic guidance at a fixed speed along a road with varying curvature. Curve negotiation performance was improved with less steering activity compared to driving the same track without haptic guidance. However, the standard deviation of the steering forces increased with haptic guidance forces present, indicating a mismatch between the drivers desired steering actions and those of the guidance system. All subjects still reported to appreciate the guidance, which also objectively shows in smoother steering behavior.

The current work is an extension of the rate hardness in [15] and quantitative metrics to characterize switch-feel in [17] where, haptic index is introduced to measure the relative hardness of actual object felt by the user at the slave gripper. The master-slave haptic gripper utilizes only one actuator for both positioning and force display, an improvement compared to [16] which utilizes separate actuators to display both position and force information at the same time. The work in [17] characterized switch-feel, in [18] characterized knob turning and in [19] improved on a steering wheel an actual object rather than just utilizing haptic for virtual objects manipulation which is the focus of many past haptic researches.

\section{HAPTIC GRIPPER SYSTEM}

The master-slave haptic gripper system as shown in Fig. 1 consists of a pair of master and slave gripper controlled by a haptic controller situated in a host computer. Each gripper is 
designed using two Futaba S5050 servomotors as the actuators. The force measurement is performed using two Honeywell FSG-15N1A force sensors per gripper. The slave gripper actual position is measured using two potentiometers. The servomotors, sensors and potentiometers are interfaced to the host computer via two microcontroller based interface boards as shown in Fig.2. The haptic controller is designed on Microsoft Visual Basic 6 platform. The haptic controller controls the position of the servomotors which effectively control the opening and closing of the master gripper's thimbles and slave gripper's thimbles.

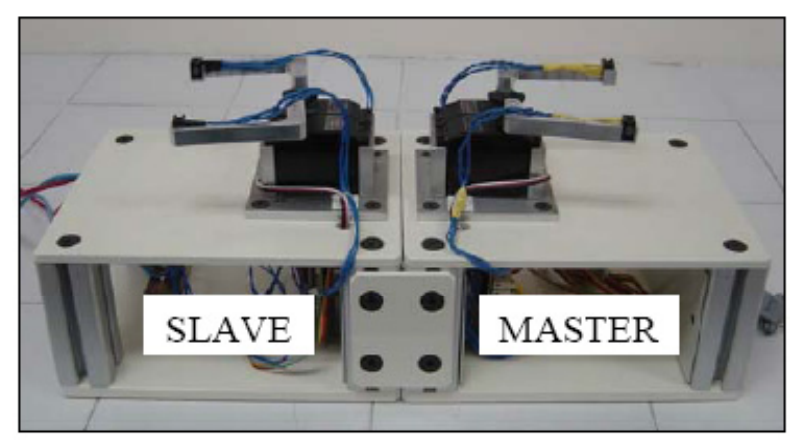

Fig.1. Master-slave haptic gripper system.

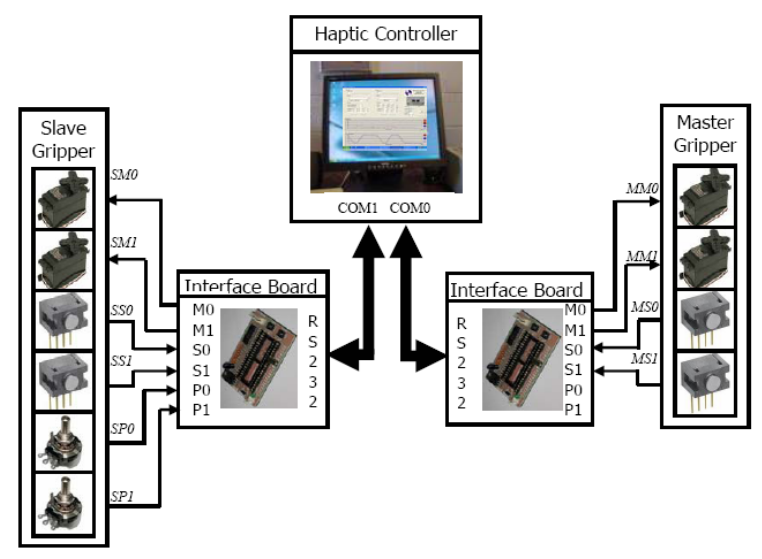

Fig. 2. Interface between the haptic controller with servomotors, sensors and potentiometers.

The thimbles' opening and closing movements are used to recreate the relative hardness feeling of the test object at slave gripper back to the user at master gripper. The haptic controller runs at an average refresh rate of $152 \mathrm{~Hz}$. At this rate, the master-slave haptic gripper is able to open and close gradually according to the intention of the user. However, the haptic gripper's refresh rate is too small to allow the gripper to follow the user's intention when the user try to close or open the gripper abruptly in less than 164 ms each way.

\section{TEST DESIGN}

\subsection{EXPERIMENTS}

Three experiments are designed to investigate the ability of the master-slave haptic gripper system to recreate the relative hardness level of six different test objects at slave gripper back to the user at master gripper. The experiments are Exp1-Relative hardness comparison using finger, Exp2-Relative hardness comparison using master-slave haptic gripper system and Exp3-The effect of time delay on the performance of the master-slave haptic gripper system. Haptic index of the six test objects are computed from the force over time data recorded from the experiments.

Fig.3 illustrates one of the users comparing the relative hardness of the test objects through the master-slave haptic gripper system. In Experiment 1 the user manipulates the test object directly while in Experiment 2 and Experiment 3 the user manipulate the test object through the master-slave haptic gripper system. Time delay is introduced into the system in Experiment 3.

The procedures for all the experiments are identical. In all the experiments, the user is required to identify the softer test object from combination of two test objects using his thumb and index finger. There are a total of fifteen combinations of two different test objects. The user is blindfolded and required to wear a headphone. It is to prevent him 
from forming his own opinion on the relative hardness of the test objects from the visual and auditory cues received. The springs are padded with rubber pads at both ends. The user is not allowed to touch the spring body to prevent him from guessing the test objects' relative hardness levels based on the tactile feedback received. The spring compression movements are fixed at $15 \mathrm{~mm}$ for all the test objects. The user is instructed to squeeze the first test object twice and proceed to squeeze the second test object twice, and identify the softer test object. The user is allowed only one retry, but is reminded that the retry will be recorded to determine his confidence level. The user is discouraged from retrying unnecessarily. The test object combinations tested and the order of softer test object appearance are at random.

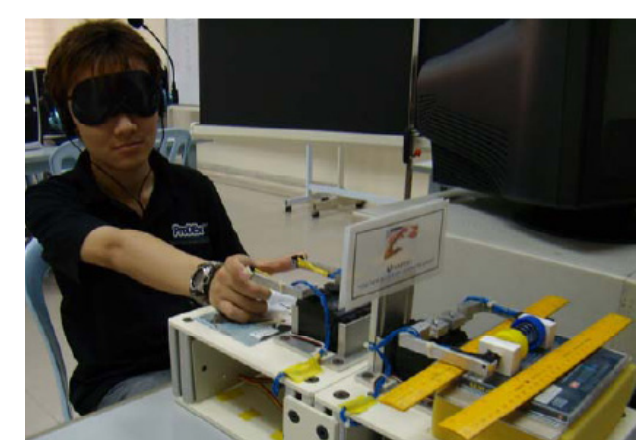

Fig. 3. One of the users comparing the relative hardness of the test objects through the master-slave haptic gripper system.

\subsection{TEST OBJECTS}

Six springs are used as test objects in the three experiments as shown in Fig. 4 Each test object has a similar $20 \mathrm{~mm}$ outer diameter, 8 active coils and $70 \mathrm{~mm}$ in length. The wire diameter of each test object ranges from 0.8 $\mathrm{mm}$ to $1.8 \mathrm{~mm}$ with an increment step of 0.2 $\mathrm{mm}$. All the lengths of the test objects are constant to prevent users from predicting the hardness or stiffness of a test object based on the distance travelled before the gripper touches the test object. Both ends of all the test objects are attached with square rubber padding to provide a consistent test surface for all the six test objects. The square rubber pads prevent users from predicting the test objects from its surface texture. The square rubber pads also prevent the round spring from rolling away when handled by the users or the slave gripper.

An experiment is conducted to measure the spring constants of the test objects. The spring constants of the test objects are summarized in Fig. 5 with Spring 1 being the softest $(0.11 \mathrm{~N} / \mathrm{m})$ and Spring 6 being the hardest $(1.43 \mathrm{~N} / \mathrm{m})$. The test objects selected range from soft to hard with close relative hardness levels to measure the performance of the master-slave haptic gripper system and the response of the users when manipulating the test objects. Besides that, spring is selected because its hardness level is measurable from the spring constant value, which can be compared against the haptic index measured from the experiments and the relative hardness level felt by the users.

Fifteen pairs of test object combinations are formed from the six test objects. As shown in Fig. 6, the combinations range from having smallest relative hardness level difference to combinations having big relative hardness level difference. Combination $1 \& 2$ has the smallest spring constant difference $(0.06$ $\mathrm{N} / \mathrm{mm}$ ), while combination $1 \& 6$ has the biggest spring constant difference (1.32 $\mathrm{N} / \mathrm{mm})$. Test object combinations $1 \& 2,1 \& 3$, $2 \& 3,3 \& 4,4 \& 5$ and $5 \& 6$ are considered having close relative hardness level difference by having spring constant difference below $0.5 \mathrm{~N} / \mathrm{mm}$ each. Test object combinations $1 \& 6,2 \& 6$ and $3 \& 6$ are considered having big relative hardness level difference by having spring constant difference above $1.0 \mathrm{~N} / \mathrm{mm}$ 
each. The test object combinations cover the diverse relative hardness characteristics to measure the performance of the master-slave haptic gripper system.

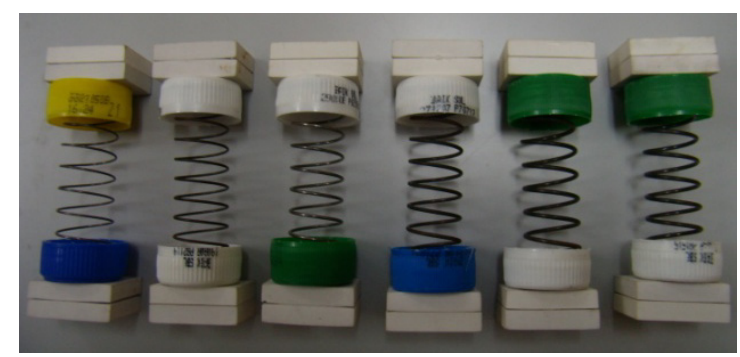

Fig. 4. Test objects used in the experiments. From left to right: $0.8 \mathrm{~mm}, 1.0 \mathrm{~mm}, 1.2 \mathrm{~mm}, 1.4 \mathrm{~mm}, 1.6 \mathrm{~mm}$ and $1.8 \mathrm{~mm}$ wire diameter.

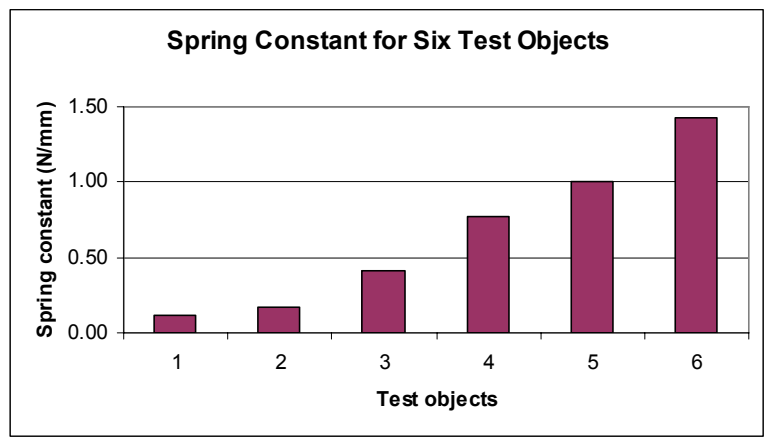

Fig. 5. Spring constant of the six test objects.

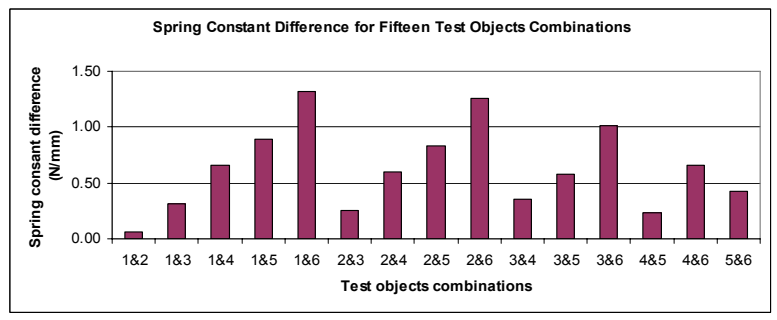

Fig. 6. Spring constant difference of the fifteen test object combinations.

\subsection{VOLUNTEER USERS}

A total of twenty volunteer users participated in the three experiments. The volunteer users are college students pursuing diploma in engineering. To prevent the variation in their biological characteristics from affecting the accuracy of the results, they are all male, of the same ethnicity, of average built and are between nineteen to twenty four years old. All the users used their dominant right hand in the experiments. They are healthy individuals with no excessive wears, cuts or abnormalities observed on their fingers and no abnormalities observed on their skin sensitivity that might affect the experiment results.

Of the twenty users, ten participated in Experiment 1. The same set of users also participated in Experiment 2. The other ten users participated in Experiment 3. Experiment 1 and Experiment 2 use the same set of users to compare their performance in identifying the softer test objects from fifteen pairs of test object combinations when using their own fingers compared to using the master-slave haptic gripper system. A new set of users is used in Experiment 3 because the previous set of ten users has already experienced handling the master-slave haptic gripper system and the test objects. Their previous experiences may help them to perform better thus affecting the accuracy of the results. The ten users in Experiment 3 are divided into two groups of five users each to measure the performance of the master-slave haptic gripper system under $5 \mathrm{~ms}$ and $10 \mathrm{~ms}$ time delay environment respectively. A different set of users is used to prevent the previous group's experience of handling the system from affecting the accuracy of the experiment.

There is no doubt that a bigger sample and female sample will indeed produce a more detailed result. However, the current male sample is sufficient for the scope of this work.

\section{EXPERIMENTAL RESULTS AND DISCUSSIONS}

\subsection{EXP1-RELATIVE HARDNESS COMPARISON USING FINGER}

The main objective of Experiment 1 is to determine users' perception of the relative hardness of the six test objects. Experiment 1 measures the ability of the users to identify the softer test object from combinations of 
two test objects. Experiment 1 also serves as a benchmark to Experiment 2 in measuring the performance of the master-slave haptic gripper system. Users' confidence level in identifying the softer test object from the test object combinations is measured.

Fig. 7 summarizes the outcome of the relative hardness comparison of the six test objects using thumb and index finger. All users except one are able to identify the softer test object from the fifteen test object combinations. Only one user found that Spring 6 is softer than Spring 5. The users' confidence in comparing the test object combinations using their thumb and index finger is summarized in Fig. 8. One user needs retry for test object combinations $2 \& 3,3 \& 4$, and $4 \& 5$. Two users need retry for test object combination $5 \& 6$. Three users need retry for test object combination $1 \& 2$. All the users need only a try for the other test object combinations.

The results show that the users have no problem in identifying the relative hardness levels of the six test objects using their thumb and index finger. Only one user has problem identifying the softer test object for object combination 5\&6. Users' confidence level drop when the relative hardness level of the test object combinations are close $(<0.5 \mathrm{~N} / \mathrm{m})$ indicating that it is more difficult for the users to identify the softer test object when the combinations have small relative hardness level difference.

It is easier for users to compare the relative hardness level of test objects with big differences $(>1.0 \mathrm{~N} / \mathrm{m})$ in their hardness level. The hardness feeling of the same test object may differ for different users due to the uniqueness of humans in having different perception of the hardness level, especially when the relative hardness levels of the test objects are close.

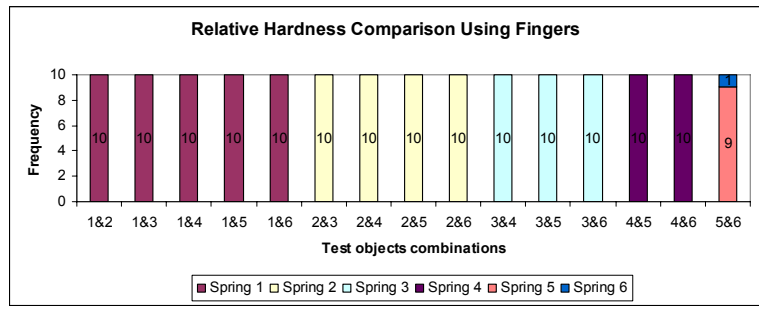

Fig. 7. Relative hardness comparison of the six test objects using thumb and index finger.

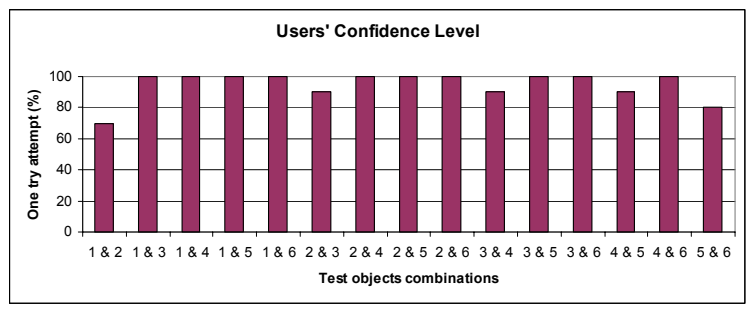

Fig. 8. Users' confidence in comparing the test object combinations using thumb and index finger.

\subsection{EXP2-RELATIVE HARDNESS COMPARISON Using MASTER-Slave HaPTIC GRIPPER SYSTEM}

The main objective of Experiment 2 is to determine the performance of the master-slave haptic gripper system in recreating the relative hardness feeling of the six test objects. Experiment 2 measures the ability of the users to identify the softer test object from a combination of two test objects through the master-slave haptic gripper system. Users' confidence levels in identifying the softer test objects from the test object combinations are recorded. The relative hardness of the six test objects felt via the master-slave haptic gripper system are measured, the data computed and presented as the haptic index discussed in the following subchapter.

Fig.9. summarizes the outcome of the relative hardness comparison of the six test objects through the master-slave haptic gripper system. All the users are able to identify the correct softer test object for combinations $1 \& 4,1 \& 5,1 \& 6,2 \& 5,2 \& 6,3 \& 4,3 \& 5$, $3 \& 6$ and $4 \& 6$. Nine users are able to identify 
the correct softer test object for combinations $1 \& 3$ and $2 \& 4$. Eight users are able to identify the correct softer object for combinations $2 \& 3$ and $4 \& 5$. Six users are able to identify the correct softer object for combination $1 \& 2$. Only five users are able to identify the correct softer object for combination $5 \& 6$.

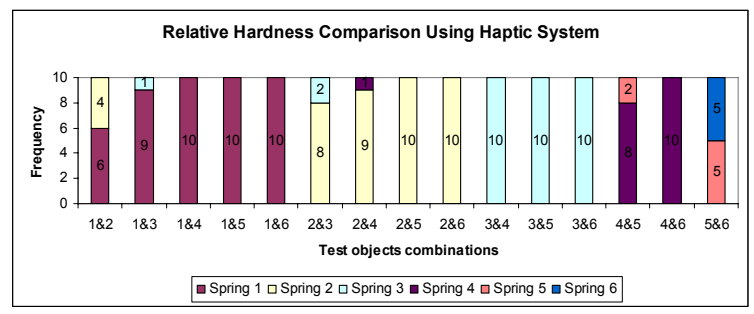

Fig. 9. Relative hardness comparison of the six test objects through the master-slave haptic gripper system.

Fig.10 summarizes the users' confidence in comparing the test object combinations through the master-slave haptic gripper system. All users need only a try for combinations $1 \& 4,1 \& 5,1 \& 6,2 \& 4,2 \& 5$, $2 \& 6,3 \& 5$ and $3 \& 6$. One user needs two tries for combination $1 \& 3$. Two users need two tries for combination $3 \& 4$. Three users need two tries for combinations $2 \& 3,4 \& 5$ and $4 \& 6$. Six users need two tries for combination $1 \& 2$. Seven users need two tries for combination $5 \& 6$.

All users are able to identify the softer test object for nine out of fifteen pairs of test object combinations. The users' ability to identify the softer test object reduces when the test object combinations have a smaller relative hardness level difference $(<0.5 \mathrm{~N} / \mathrm{m})$. The users failed to identify the softer object for combinations $1 \& 2$ and $5 \& 6$ which have very close relative hardness level of $0.06 \mathrm{~N} / \mathrm{m}$ and $0.43 \mathrm{~N} / \mathrm{m}$ respectively. The users' confidence in identifying the softer test object reduces when the combinations have a smaller relative hardness level difference. The trend of the result obtained is similar to Experiment 1 except that the users performed better in Experiment 1 which is the benchmark experiment. From the results observed, it can be safely deduced that the master-slave haptic gripper system, is able to recreate the relative hardness feeling of the six test objects from the slave gripper back to the users at the master gripper.

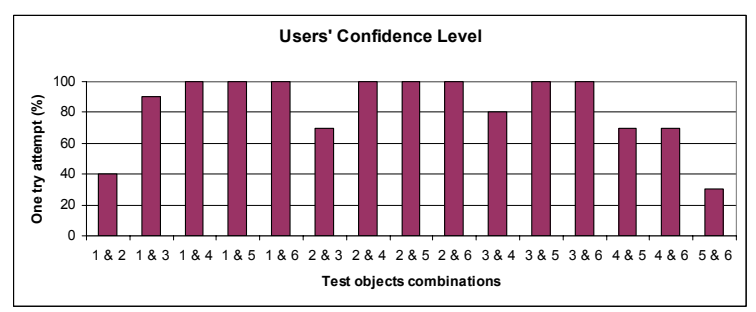

Fig. 10. Users' confidence in comparing the test object combinations through the master-slave haptic gripper system.

5.3 EXP3-The EFfect of Time Delay ON THE Performance of the Master-Slave Haptic GRIPPER SYSTEM

The performance of any haptic system is very much dependent on the operating frequency of the system. Besides the hardware and software overheads, the time delay while transmitting data over long distances from the master gripper to the slave gripper and vice versa reduces the operating frequency of the system. A haptic system will not be able to recreate a realistic feeling when operated at a reduced frequency. Its performance becomes sluggish and unstable. However, the current master-slave haptic gripper being a laboratory prototype with a short distance data transmission is less affected by the time delay problem. Nevertheless, the issue of time delay will be apparent when the system is eventually expanded to include long distance communication. A limited study is conducted to evaluate the performance of the masterslave haptic gripper system under time delay condition. Preliminary test shows that the performance of the master-slave haptic gripper deteriorates as its operating frequency 
decreases. However, to pin point exactly when the system will cease to perform effectively is rather difficult considering the different abilities of the users in identifying the softer test object from the test object combinations, the different test object combinations with a diverse relative hardness levels and the different groups of users involved. An experiment similar to Experiment 2 may be conducted at every time interval eg. $0.5 \mathrm{~ms}$ until the system ceases to perform effectively. However, this approach is laborious needing a new set of users at each time interval. It is observed from the preliminary test that the master-slave haptic gripper's performance deteriorates rather significantly when the time delay is more than $5 \mathrm{~ms}$ and ceases to perform at $10 \mathrm{~ms}$. Hence, Experiment 3 is designed to measure the performance of the master-slave haptic gripper system when subjected to $5 \mathrm{~ms}$ and $10 \mathrm{~ms}$ time delay.

Fig. 11 summarizes the outcome of the relative hardness comparison of the six test objects through the master-slave haptic gripper system when subjected to $5 \mathrm{~ms}$ time delay. All the users are able to identify the correct softer test object for combinations $1 \& 4,1 \& 6,2 \& 5$, and $2 \& 6$ only. Four users are able to identify the correct softer object for combinations $1 \& 5$ and $3 \& 6$. Three users are able to identify the correct softer object for combinations $1 \& 3,2 \& 4,3 \& 4,3 \& 5$ and $4 \& 5$. Only two users are able to identify the correct softer object for combinations $1 \& 2$, $2 \& 3,4 \& 6$ and $5 \& 6$. The users' confidence level deteriorates where the users need two tries for all the test object combinations. Fig. 12 summarizes the outcome of the relative hardness comparison of the six test objects through the master-slave haptic gripper system when subjected to $10 \mathrm{~ms}$ time delay. All the test objects appear hard and the haptic gripper system performs erratically.
The users are not able to identify the softer test object and have indicated that they are just guessing the hardness level.

The master-slave haptic gripper system performs the best without the effect of time delay. Its performance deteriorates when subjected to $5 \mathrm{~ms}$ time delay. The haptic system ceases to perform reliably at time delay of $10 \mathrm{~ms}$.

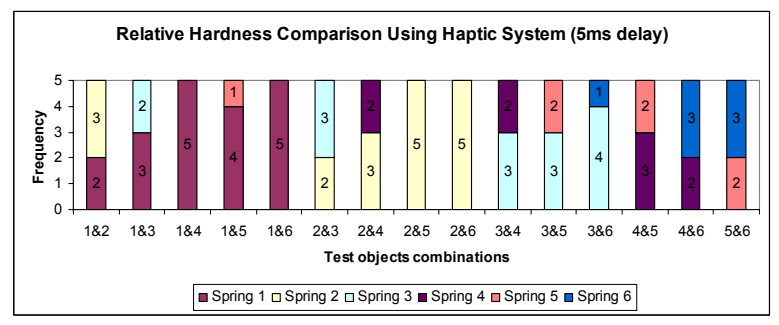

Fig. 11. Relative hardness comparison of the six test objects through the master-slave haptic gripper system

( $5 \mathrm{~ms}$ time delay).

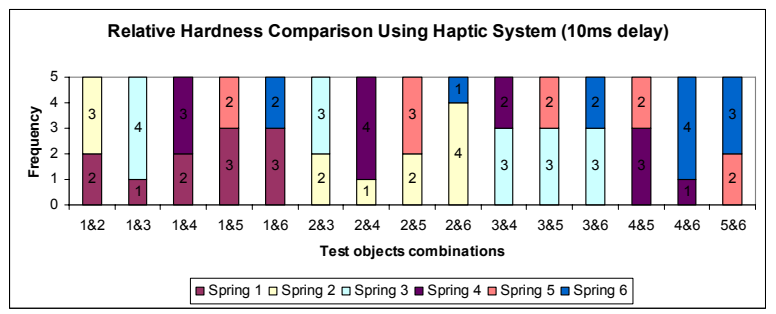

Fig. 12. Relative hardness comparison of the six test objects through the master-slave haptic gripper system

(10ms time delay).

\subsection{HAPTIC INDEX}

Haptic index is first introduced in this work as the rate of force applied to an object to provide a quantitative value to the otherwise qualitative relative hardness level felt by human. In the physical world, the hardness level of objects can be determined using various methods like the different types of tensile tests and hardness tests. However, when it is the robotic finger gripping an object, it is difficult for the robot controller to determine the relative hardness of the object. Therefore, haptic index can be used to help the robot controller determine the relative hardness level of the object while handling it. 
This numerical value is essential in the development of haptic robots that are able to sense like humans instead of the binary-like sensing, "hard" or "soft". Haptic index will be useful when robots start working alongside humans at home where there will be a lot of interactions with the surrounding environment of different relative hardness level, for example, furniture, mattresses, cushions, walls, toys, pets, children, etc. Another possible application will be in the manufacturing sector where a sample of products are often taken offline to perform hardness test, often destructive testing. If the similar technique in determining haptic index can be incorporated in the production line using suitable sensors, $100 \%$ non destructive test can be performed on the products thus increasing throughput and reliability of the products.

Fig. 13 illustrates the feedback force against time graph of six test objects for a particular user. It is observed that when the slave gripper starts engaging the surface of the test object, a feedback force is reflected to the slave gripper. The feedback force is measured by the two force sensors attached to the two thimbles of the slave gripper. The feedback force starts increasing once the slave gripper comes into contact with the surface of the test object. The feedback force keeps increasing as the user squeeze into the object. The feedback force flattened when the user reaches the maximum closing limit of the slave gripper. The feedback force reduces when the user starts releasing the slave gripper until the slave gripper is at fully open position. The feedback force reflected from the test object creates the perception of relative hardness felt by the user. In this work, the master-slave haptic gripper artificially recreates the feedback force measured at slave gripper back to the user at master gripper. This feedback force at the master gripper tricks the user into believing that he/she is squeezing an actual object instead of remotely squeezing an object through the haptic device.

It is observed that, the degree of relative hardness of the test object felt by the user is related to the gradient of the positive slope of the feedback force against time graph of the particular test object. Harder test objects produce a steeper slope while softer test objects produce a gentler slope. The same graph slope pattern can be observed throughout the six test objects for the ten users. The haptic index of the six test objects are computed from the average positive slope values of the feedback force against time graph of the ten users. Fig. 14 summarizes the haptic index of the six test objects. Spring 1 is the softest with a haptic index of $11 \mathrm{~N} / \mathrm{s}$, followed by Spring 2 (19 N/s), Spring 3 (39 $\mathrm{N} / \mathrm{s})$, Spring $4(54 \mathrm{~N} / \mathrm{s})$, Spring $5(69 \mathrm{~N} / \mathrm{s})$, and Spring $6(80 \mathrm{~N} / \mathrm{s})$ the hardest test object. The standard deviation for the measurement of Spring 1's haptic index is 2.7 , followed by Spring 2 (5.7), Spring 3 (8.6), Spring 4 (15.8), Spring 5 (12.6), and Spring 6 (11.5). Fig. 15 summarizes the haptic index difference between different test object combinations. Combinations 1\&2, 2\&3, 3\&4, 4\&5 and $5 \& 6$ have small haptic index difference indicating that the combinations have close relative hardness level. Combinations $1 \& 5$, $1 \& 6$ and $2 \& 6$ have large haptic index difference indicating that the combinations have large relative hardness differences.

It is observed in Fig. 5, that the test objects has a spring constant trend of lowest spring constant value for the softest test object increasing to the highest spring constant value for the hardest test object. Similarly in Fig. 14, the test objects has a haptic index trend of lowest haptic index value for the softest test object increasing to the highest haptic index 
value for the hardest test object. Comparing Fig. 5 with Fig. 14, shows that the trend of the haptic index of the six test objects proposed in this work, agrees with the relative hardness level of the test objects verified by their spring constant values. Similarly, comparing Fig. 6 with Fig. 15, shows that the trend of the haptic index difference of the fifteen test object combinations agrees with the relative hardness difference of the test object combinations verified by their spring constant difference values.

Haptic index is a measurable parameter to represent the otherwise not measurable feeling of relative hardness felt by human towards an object. The haptic index measured in this work is consistent with the experimental results and the spring constant of the test objects.

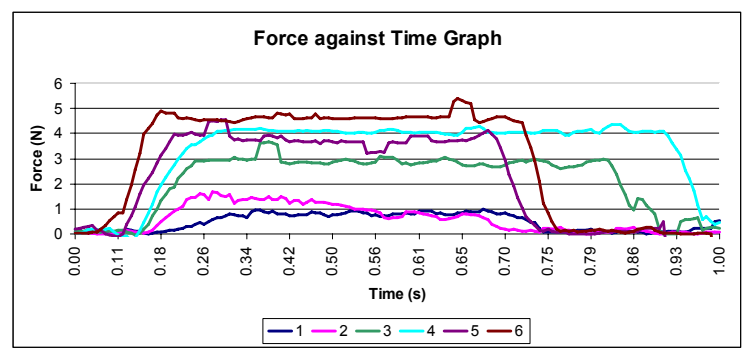

Fig. 13. Feedback force against time graph when the gripper engages the test objects.

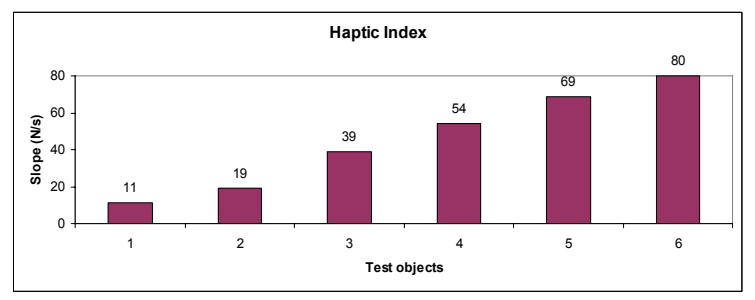

Fig. 14. Haptic index of the six test objects.

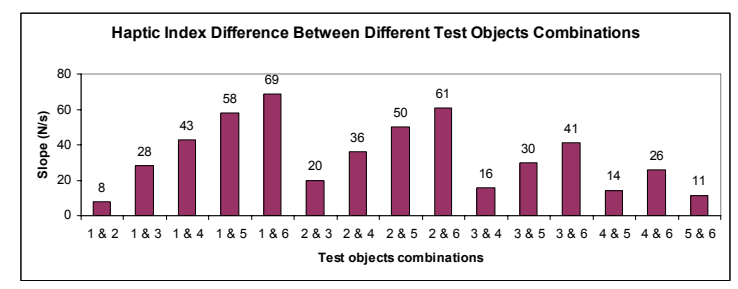

Fig. 15. Haptic index difference between different test object combinations.

\section{CONCLUSION AND FUTURE WORK}

This work proved that it is able to recreate the relative hardness feeling of actual object at slave gripper back to the user at master gripper. The results of Experiment 1 and Experiment 2 have shown that the masterslave haptic gripper system is able to recreate the relative hardness feeling of the six test objects back to the users at master gripper. The positioning and force feedback of the master-slave haptic gripper is accomplished by using only one servomotor per degree-offreedom. Haptic index is introduced as a quantitative value to the otherwise qualitative relative hardness level. Haptic index of the six test objects are computed.

However, there are some limitations, and improvements related to its operating frequency and the effect of time delay needs to be done to further enhance the sensitivity and responsiveness of the current system. The investigation on haptic index need to be further extended on the improved haptic system incorporating more diverse test objects and users. The size of the current prototype needs to be reduced drastically in order to be incorporated into commercial products. This work is a step towards the advancement of haptic research.

\section{ACKNOWLEDGEMENT}

This work is supported by an internal research grant from Multimedia University, Malaysia.

\section{REFERENCES}

[1] Richard, P. and Coiffet, Ph., "Dextrous Haptic Interaction in Virtual Environments: Human Performance Evaluations", Proc. of the 1999 IEEE Int. Workshop on Robot and Human Interaction, 1999, pp. 315-320.

[2] Trumble, W. J. and Stevenson, A. (Ed.)., "Shorter Oxford English Dictionary", 5th ed., Vol. 3, USA: Oxford University Press, 2002. 
[3] Adachi, Y., Kumano, T. and Ogino, K., "Intermediate Representation for Stiff Virtual Objects", Proc. of the Virtual Reality Annual Int. Symp, 1995, pp. 203-210.

[4] Kawasaki, H., Takai, J., Tanaka, Y., Mrad, C. and Mouri, T., "Control of Multi-Fingered Haptic Interface Opposite to Human Hand", Proc. of the IEEE Int. Conf. on Intelligent Robots and Systems, 2003, pp. 2707-2712.

[5] Moy, G., Wagner, C. and Fearing, R. S., "A Compliant Tactile Display for Teleaction", Proc. of the IEEE Int. Conf. on Robotics and Automation, 2000, pp.3409-3415.

[6] Manukid Parnichkun, Watcharin Pongern and Thira Jearsiripongkul, "Development of a ForceDisplacement Controlled Medical Tele-Analyser", Proc. of the ISIE, 2001, pp.1978-1981.

[7] Barbagli, F., Salisbry, K. Jr. and Devengenzo, R., "Enabling Multi-finger, Multi-hand Virtualized Grasping", Proc. of the IEEE Int. Conf. on Robotics and Automation, 2003, pp. 809-815.

[8] Wang, D., Tuer, K., Ni, L. and Porciello, P., "Conducting a Real-Time Remote Handshake with Haptics", Proc. of the IEEE Int. Symp. on Haptic Interfaces for Virtual Environment and Teleoperator Systems, 2004, pp. 291.

[9] Takasaki, M., Nara, T., Tachi, S. and Higuchi, T., "A Tactile Display Using Surface Acoustic Wave", Proc. of the IEEE Int. Workshop on Robot and Human Interactive Communication, 2000, pp. 364-367.

[10] Immersion Corp. (2008, Jan). Immersion Corporation Website [Online]. Available: http://www.immersion.com/

[11] Sensable Technologies. (2008, Jan). Sensable Technologies Website [Online]. Available: http://www.sensable.com/

[12] Wagner, C. R., Lederman, S. J. and Howe, R. D., "A Tactile Shape Display Using RC Servomotors", Proc. of the IEEE Symp. on Haptic Interfaces for Virtual Environment and Teleoperator Systems, 2002, pp. 354-355.

[13] Rakkanen, T., Raisamo, R., Raisamo, J., Salminen, K., and Surakka, V., "Comparison of Three Designs for Haptic Button Edges on Touchscreens", Proc. of the IEEE Symp. on Haptics, 2010, pp. 219-225.

[14] Samra, R., Wang, D., and Zadeh, M. H., "Design and Evaluation of a Haptic Tactile Actuator to Simulate Rough Textures", Proc. of the IEEE Conf. on Virtual Reality, 2010, pp. 301302.

[15] Lawrence, D. A., Pao, L. Y., Dougherty, A. M., Salada, M. A., and Pavlou, Y., "Rate-Hardness: A New Performance Metric for Haptic Interfaces", IEEE Trans. on Robotics and Automation, 1999, pp. 357-371.

[16] Kikuuwe, R. and Yoshikawa, T., "Haptic Display Device with Fingertip Presser for Motion/Force Teaching to Human", Proc. of the IEEE Int. Conf. on Robotics and Automation, 2001, pp. 868-873.

[17] Weir, D. W., Peshkin, M. A., Colgate, J. E. and Buttolo, P., "Design and Performance of a High Fidelity, Low Mass, Linear Haptic Display”, Proc. of the First Joint Eurohaptics Conf. and Symp. on Haptic Interfaces for Virtual Environment and Teleoperator Systems, 2005, pp. 177-182.

[18] Nam, Y. J., and Park, M. K., “A Hybrid Haptic Device for Wide-Ranged Force Reflection and Improved Transparency", Proc. of the Int. Conf. on Control, Automation and Systems, 2007, pp. 1015-1020.

[19] Mulder, M., Abbink, D. A., and Boer, E. R., "The Effect of Haptic Guidance on Curve Negotiation Behaviour of Young, Experienced Drivers", Proc. of the IEEE Int. Conf. on Systems, Man and Cybernetics, 2008, pp. 804-809. 


\title{
خلق وقياس الإحساس النسبي بالصلابة من خلال اللمس والقبض بأسلوب السيد-الخادم
}

\author{
تي تيونج تاب' و كيونغ ونج

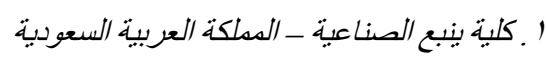

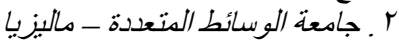

الملخص:

يهذف هذا العمل إلى تصميم وتحليل نظام لخلق وقياس الإحساس النسبي بالصلابة لأجسام مختلفة بإستخدام قابض خادم وقابض سيد. ويعتبر الإنجاز الرئيسي في هذا البحث هو إثبات جدوى إعادة خلق الإحساس النسبي بالصلابة لأجسام مختلفة من خلال أجسام تخيلية. تم إجراء ثلاثة تجارب تحتوي على عشرين إختبار وخمسة عشر زوج من أجسام الإختبار لكي نصل إلى تقييم الإحساس باللمس و القبض بأسلوب السيد_الخادم. ولقد أثبتت التجارب إمكانبة إحساس القابض السيد بالمفاضلة بين الصلابة النسبية لأجسام إختبار من خلال مقابض الخادم. يمكن الإستفادة من نتائج هذا البحث في تصميم أفضل للإنسان الآلي لكي يستطيع الإحساس النسبي بالصلابة لأجسام مختلفة تمامأ كإحساس الإنسان البشري. 